\title{
Matemática na Educação de Jovens e Adultos: análise da produção científica do período 2004-2015
}

\section{RESUMO}

Giane Correia Silva gianecorreia@hotmail.com 0000-0002-9724-8496 Ponta Grossa Prossa, Paraná, Brasil.

\section{Mary Ângela Teixeira Brandalise} marybrandalise@uol.com.br

Universidade Estadual de Ponta Grossa Ponta Grossa, Paraná, Brasil
Este artigo apresenta os resultados de uma pesquisa qualitativa, a qual teve um caráter de revisão sistemática de produções científicas sobre Matemática na Educação de Jovens e Adultos - EJA, publicadas no Brasil no período 2004-2015. No levantamento realizado em meio eletrônico, foram localizados 68 trabalhos, os quais foram organizados conforme a natureza, o ano de publicação, a instituição de origem, o título e a autoria. Na sequência, foram agrupados conforme a similaridade dos temas de pesquisa, procedimento que originou cinco categorias: atuação e prática do professor de matemática; ensinoaprendizagem de Estatística; ensino-aprendizagem de Matemática; formação de professores de Matemática e currículo de Matemática. A organização de todos os resumos em único corpus textual e a análise de conteúdo no software IRAMUTEQ, possibilitou as análises lexicográficas e de similitude, evidenciando a concentração das pesquisas sobre o ensino-aprendizagem de matemática na EJA.

PALAVRAS-CHAVE: Matemática. Educação de jovens e adultos - EJA. Revisão sistemática. 


\section{INTRODUÇÃO}

A partir da promulgação da Lei de Diretrizes e Bases da Educação Nacional em 1996 (LDBEN 9394/1996), da publicação das Diretrizes Curriculares para a Educação de Jovens e Adultos (BRASIL, 2000a, 2000b), da proposta curricular para EJA 1은 Segmento (BRASIL, 2001) e 20 Segmento (BRASIL, 2002) e dos cadernos temáticos da Coleção "Trabalhando com a Educação de Jovens e Adultos" (BRASIL, 2006), as pesquisas em torno da Educação de Jovens e Adultos - EJA se intensificaram no cenário educacional brasileiro.

O Ministério da Educação criou em 2004, a Secretaria de Educação Continuada Alfabetização e Diversidade (SECAD), com o objetivo de garantir políticas públicas como instrumentos de cidadania e de contribuição para a redução das desigualdades sociais, a fim de atenuar a dívida histórica que o Brasil tem para com todos os cidadãos de 15 anos ou maisque não concluíram a Educação Básica.

Embora a EJA tenha características próprias, diferenciadas das modalidades regulares de ensino, são poucos os cursos de formação de professores e universidades que oferecem formação específica aos que desejam trabalhar ou já trabalham nessa modalidade de ensino. Essa carência de formação e de publicações, desencadearam a necessidade de investigações voltadas ao ensino e aprendizagem, a formação dos professores, as metodologias de ensino, a elaboração de materiais didáticos e aos currículos das disciplinas da EJA.

Nesse contexto é que se insere a pesquisa voltada à análise das produções científicas sobre a EJA relacionadas à área de Matemática. A investigação integra uma pesquisa mais ampla, que trata do "Ensino de Estatística na Educação de Jovens e Adultos: currículo e práticas pedagógicas", desenvolvida na linha de pesquisa Políticas Curriculares e Ensino de Matemática, do grupo Política Educacional e Avaliação, do Programa de Pós-Graduação em Educação da Universidade Estadual de Ponta Grossa - PPGE/UEPG.

O levantamento de teses e dissertações sobre a EJA e a Matemática foi realizado com a finalidade de inventariar, por um lado, a produção acadêmica já realizada no contexto brasileiro tendo como objeto de estudo o Ensino de Estatística e por outro lado, de expandir, organizar e difundir essa produção acadêmica, bem como analisá-la por diferentes aspectos: os temas abordados, as contribuições desses trabalhos para a compreensão das diferentes temáticas relacionadas à Matemática na EJA, os referenciais teóricos adotados, os problemas e as lacunas de pesquisas.

Neste artigo apresentam-se os principais resultados do levantamento realizado, o qual envolveu o mapeamento de teses e dissertações sobre a EJA, relacionados à área de Matemática, defendidas no período de 2004 a 2015. Tal procedimento se justifica porque o Ensino de Estatística está contemplado no bloco de conteúdo denominado "Tratamento da Informação", que integra os Parâmetros Curriculares Nacionais para área de Matemática, juntamente com os blocos "Números e Operações, Espaço e Forma, Grandezas e Medidas".

Considerando o objeto da pesquisa, a questão norteadora que se pretendeu responder foi: quais foram as pesquisas realizadas na EJA, relacionadas à área de Matemática, desenvolvidas na forma de dissertações e teses no contexto brasileiro nos últimos doze anos? 
Diante do crescimento constante de pesquisas, argumenta-se que o levantamento e a análise aprofundada dessa produção adquirem significado e relevância porque podem: a) subsidiar uma avaliação dos possíveis avanços e contribuições da produção acadêmica para uma maior compreensão da EJA relacionada à componente curricular de Matemática em particular, sobre o Ensino e aprendizagem de Estatística; b) propiciar sínteses importantes sobre os temas investigados; c) apontar questões pertinentes a realização de novas pesquisas, de reformulações curriculares, de reflexões sobre as práticas docentes e de (re)formulação de políticas educacionais.

\section{PROCEDIMENTOS METODOLÓGICOS}

Nos últimos anos têm-se observado um movimento de expansão acentuada nas pesquisas em Educação Matemática. Há um interesse cada vez mais crescente nessa área de pesquisa envolvendo diferentes aspectos e temas sobre ensinoaprendizagem, formação de professores, currículos, políticas de formação, metodologias de ensino, dentre outros. Com aumento da produção científica nos programas de pós-graduação no Brasil - teses, dissertações -, diferentes temas e modalidades de ensino da Educação Básica até a Educação Superior tem sido objeto de estudos e pesquisas, dentre elas a EJA.

Questões relacionadas à área de Matemática, na EJA, também têm se intensificado nas pesquisas brasileiras, a fim de contribuir com as especificidades didático-pedagógicas que essa modalidade de ensino requer. Nos documentos oficiais emanados do Ministério da Educação do Brasil são dadas diretrizes e orientações relevantes para os professores atuarem nas escolas, mas certamente existem lacunas, dificuldades e desafios para a efetivação de um ensino adequado nas características dos alunos que retornam aos estudos na fase adulta.

A necessidade de realizar um balanço sobre a produção de conhecimento já elaborado pelos pesquisadores carece de um mapeamento, uma revisão dos temas pesquisados para "apontar caminhos que vêm sendo tomados e aspectos que são abordados em detrimento de outros. A realização destes balanços possibilita contribuir com a organização e análise na definição de um campo, uma área" (ROMANOWSKI; ENS, 2006, p.39). Portanto, estudos voltados à sistematização da produção numa determinada área do conhecimento são fundamentais para que se possa apreender a amplitude do que vem sendo pesquisado e produzido.

O presente texto se insere nessa categoria de revisão sistemática de produções científicas, com natureza exploratória e preliminar, pois objetiva elaborar uma síntese da pesquisa sobre EJA relacionada à Matemática. Segundo Mainardes (2006, p.8) a revisão sistemática visa "mapear as pesquisas sobre determinado tópico, bem como sintetizar as temáticas abordadas, as abordagens teórico-metodológicas empregadas, tendências gerais de investigação, contribuições dos estudos, lacunas e sínteses das conclusões".

Os resumos das produções mapeadas foram analisados em três etapas: na primeira etapa as produções científicas foram organizadas conforme a natureza, o ano de publicação, a instituição de origem, o título e autoria. Na segunda etapa os pesquisa, procedimento que originou cinco categorias de análise. A organização de 
todos os resumos em único corpus textual, e a análise de conteúdo no software IRAMUTEQ, constituiu a terceira etapa.

\section{MAPEAMENTO E CATEGORIZAÇÃO DAS PESQUISAS}

A localização das produções científicas publicadas no período 2004-2015, relacionadas à Matemática na EJA, no Brasil, foi realizada em meio eletrônico nas seguintes bases: Banco de Teses da Capes, BDTD - Biblioteca de Teses e Dissertações e Domínio Público - Teses e Dissertações.

No levantamento realizado foi utilizado o descritor "Matemática e Educação de Jovens e Adultos". A busca resultou em 68 fontes (documentos), entre dissertações (65 - 96\%) e teses (3 - 4\%). A distribuição das produções acadêmicas mapeadas no período está apresentada no quadro 1, abaixo:

Quadro 1 - Teses e dissertações defendidas no período 2004-2015

(continua)

\begin{tabular}{|c|c|c|c|c|}
\hline Ano & Teses & Dissertações & Total & (\%) \\
\hline 2004 & - & 4 & 4 & 5,9 \\
\hline 2005 & - & 1 & 1 & 1,5 \\
\hline 2006 & - & 5 & 5 & 7,4 \\
\hline 2007 & - & 8 & 8 & 11,8 \\
\hline 2008 & 1 & 6 & 7 & 10,3 \\
\hline 2009 & - & 4 & 4 & 5,9 \\
\hline 2010 & - & 4 & 4 & 5,9 \\
\hline 2011 & 1 & 14 & 15 & 22,0 \\
\hline 2012 & 1 & 12 & 13 & 19,0 \\
\hline
\end{tabular}

(conclusão)

\begin{tabular}{|c|c|c|c|c|}
\hline Ano & Teses & Dissertações & Total & $\mathbf{( \% )}$ \\
\hline 2013 & - & 3 & 3 & 4,4 \\
\hline 2014 & - & 3 & 3 & 4,4 \\
\hline $2015^{*}$ & - & 1 & 1 & 1,5 \\
\hline Total & $\mathbf{3}$ & $\mathbf{6 5}$ & $\mathbf{6 8}$ & $\mathbf{1 0 0 ( \% )}$ \\
\hline
\end{tabular}

(Fonte: Dados da pesquisa. Nota: Trabalhos defendidos até junho de 2015)

Os 68 trabalhos incluídos nesta revisão são oriundos de treze estados brasileiros, com maior produção nos programas de pós-graduação dos estados de São Paulo (32\%), Rio Grande do Sul (19\%), Minas Gerais (13\%) e Rio Grande do Norte (9\%), e com produções menores nos estados: Rio de Janeiro, Paraná, Santa Catarina, Pernambuco, Pará, Amazonas, Bahia e Brasília. As pesquisas realizadas foram abordadas por diferentes aspectos e perspectivas metodológicas.

Um banco de dados foi criado com os resumos de cada trabalho localizado a fim de contar uma história de sua produção acadêmica, embora esse tipo de análise tenha suas limitações, pois: 
Eles trazem, enquanto gênero do discurso, um conteúdo temático, que é o de apresentar aspectos das pesquisas a que se referem; trazem uma certa padronização quanto à estrutura composicional: anunciam o que se pretendeu investigar, apontam o percurso metodológico realizado, descrevem os resultados alcançados. [...]. De todo modo, pode-se estabelecer a partir de uma certa ordenação de resumos uma rede formada por diferentes elos ligados a partir do mesmo suporte material que os abriga, pela opção teórica manifesta, pelo tema que anuncia, pelo objetivo explicitado da pesquisa, pelo procedimento metodológico adotado pelo pesquisador. Um conjunto de resumos organizados em torno de uma determinada área do conhecimento (Alfabetização, Leitura, Formação do Professor, Educação Matemática, por exemplo) pode nos contar uma História de sua produção acadêmica. Mas, é necessário pensar que nesta História foram considerados alguns aspectos dessa produção e que nela há certas limitações. (FERREIRA, 2000, p.268).

Ao realizar a leitura e análise dos resumos das produções acadêmicas coletadas foram considerados os objetos de estudo e as palavras-chave neles definidas. A partir desse processo foi constatado que as produções acadêmicas já realizadas trataram da Atuação e Prática do Professor de Matemática, do Currículo de Matemática, da Formação de Professores de Matemática e do Ensinoaprendizagem de Matemática, evidentemente todos relacionados à EJA.

A maior ocorrência foi de pesquisa sobre o ensino-aprendizagem de Matemática, envolvendo diferentes aspectos do conhecimento matemático e suas metodologias. Considerando que o levantamento realizado faz parte da pesquisa "Ensino de Estatística na Educação de Jovens e Adultos: currículo e práticas pedagógicas", optou-se pela categorização das teses e dissertações agrupando aquelas que se referiam ao ensino-aprendizagem de Estatística numa categoria, e as demais como ensino-aprendizagem de Matemática.

Desta forma, o material inventariado ficou organizado em cinco categorias conforme apresentado no Quadro 2.

Quadro 2- Categorização das teses e dissertações sobre Matemática na EJA - 2004-2015

\begin{tabular}{|l|l|c|c|c|c|}
\hline $\begin{array}{l}\text { Códi } \\
\text { go }\end{array}$ & Categorias & Teses & $\begin{array}{l}\text { Disserta } \\
\text { ções }\end{array}$ & $\begin{array}{l}\text { To } \\
\text { tal }\end{array}$ & $\begin{array}{l}\text { Total } \\
\text { (\%) }\end{array}$ \\
\hline A & $\begin{array}{l}\text { Atuação e prática } \\
\text { do professor de } \\
\text { Matemática }\end{array}$ & 1 & 5 & 6 & 9 \\
\hline B & $\begin{array}{l}\text { Ensino- } \\
\text { aprendizagem de } \\
\text { Estatística }\end{array}$ & 0 & 4 & 4 & 6 \\
\hline C & $\begin{array}{l}\text { Ensino- } \\
\text { aprendizagem de } \\
\text { Matemática }\end{array}$ & 2 & 44 & 46 & 67 \\
\hline D & $\begin{array}{l}\text { Formação de } \\
\text { professores de } \\
\text { Matemática }\end{array}$ & 0 & 4 & 4 & 6 \\
\hline E & $\begin{array}{l}\text { Currículo de } \\
\text { Matemática }\end{array}$ & 0 & 8 & 8 & 12 \\
\hline & Total & $\mathbf{3}$ & $\mathbf{6 5}$ & $\mathbf{6 8}$ & $\mathbf{1 0 0}$ \\
\hline
\end{tabular}

(Fonte: Dados da pesquisa) 
As cinco dissertações que compuseram a categoria "Atuação e prática do professor de Matemática" (A) foram: 1) A atuação e prática do professor de Matemática na EJA : conhecendo a problemática. 2) Saberes construídos pelos professores de Matemática em sua prática docente na EJA. 3) A Matemática e a construção da cidadania na EJA: concepções de professores que atuam no ensino médio em Cuiabá e Várzea Grande - MT. 4) Inclusão-exclusão nas práticas pedagógicas dos professores que ensinam Matemática na EJA. 5) Práticas avaliativas em Matemática na EJA: estudo de caso de uma escola da rede municipal de Belo Horizonte. Também faz parte dessa categoria a tese: "Propondo práticas e desafiando certezas: um estudo em turma do PROEJA numa perspectiva de Educação Matemática Crítica".

A segunda categoria (B) refere-se a quatro trabalhos que tematizam o "Ensinoaprendizagem Estatística" na EJA. São elas: 1) Aprendizagem de Estatística na EJA com tecnologia: uma sequência didática com base nos registros de representação semiótica. 2) Uma sequência didática para o ensino de Estatística a alunos do Ensino Médio na modalidade PROEJA. 3) EJA: aprendizagem de conceitos estatísticos através de atividades práticas e conhecimento prévio. 4) O papel da Estatística na inclusão de alunos da EJA em atividades letradas.

Na categoria "Ensino-aprendizagem de Matemática" (C) estão reunidos duas teses e quarenta e quatro dissertações. As teses foram "Aprender matemática na EJA: a arte de sentir e dos sentidos" e "Gênero e matemática(s): jogos de verdade nas práticas de numeramento de alunas e alunos da educação de pessoas jovens e adultas". As dissertações contemplaram temas e objetos de pesquisas variados, que possibilitam outras categorizações. A relação das dissertações está apresentada no quadro 3: 


\begin{tabular}{|c|c|}
\hline $\begin{array}{l}\text { Sub } \\
\text { Categorias }\end{array}$ & Título das produções \\
\hline Álgebra & $\begin{array}{l}\text { Introdução do pensamento algébrico para alunos do EJA: uma } \\
\text { proposta de ensino. }\end{array}$ \\
\hline Álgebra & $\begin{array}{l}\text { Análise de produção escrita de estudantes da EJA em atividades } \\
\text { algébricas. }\end{array}$ \\
\hline Etnomatemática & A Etnomatemática em uma sala da EJA: a experiência do pedreiro. \\
\hline Geometria & $\begin{array}{l}\text { Geometria Plana e Inclusão Digital: uma experiência a partir do } \\
\text { cotidiano dos alunos EJA. }\end{array}$ \\
\hline Geometria & $\begin{array}{l}\text { Professores de Matemática na EJA: o pensamento geométrico no } \\
\text { centro das atenções. }\end{array}$ \\
\hline Geometria & $\begin{array}{l}\text { As aplicações e contribuições da Geometria Plana na EJA no ensino } \\
\text { fundamental por meio de unidade de aprendizagem. }\end{array}$ \\
\hline Geometria & $\begin{array}{l}\text { Aprendizagem de Geometria a partir de saberes, vivências e } \\
\text { interações de alunos da EJA numa escola pública. }\end{array}$ \\
\hline Geometria & $\begin{array}{l}\text { A aprendizagem da Geometria por meio do estudo do cubismo no 5을 } \\
\text { ano da EJA. }\end{array}$ \\
\hline Jogos & ática sob a ótica do Tarô: uma experiência com a EJA. \\
\hline Jogos & $\begin{array}{l}\text { A contribuição do jogo de xadrez para o ensino de coordenadas } \\
\text { cartesianas na EJA. }\end{array}$ \\
\hline Jogos & $\begin{array}{l}\text { Linguagem Matemática e jogos: uma introdução ao estudo de } \\
\text { expressões algébricas e equações do } 1 \text { o grau para alunos da EJA. }\end{array}$ \\
\hline $\begin{array}{l}\text { Material } \\
\text { Didático }\end{array}$ & $\begin{array}{l}\text { As dificuldades do uso do vídeo em aulas de matemática na EJA no } \\
\text { município de Goiano-PE. }\end{array}$ \\
\hline $\begin{array}{l}\text { Material } \\
\text { Didático }\end{array}$ & $\begin{array}{l}\text { Globos e mapas ao alcance das mãos: ensino de matemática numa } \\
\text { perspectiva de alfabetização funcional na EJA. }\end{array}$ \\
\hline $\begin{array}{l}\text { Material } \\
\text { Didático }\end{array}$ & $\begin{array}{l}\text { Uso do vídeo no ensino de Matemática: aplicações na EJA no Ensino } \\
\text { Médio. }\end{array}$ \\
\hline $\begin{array}{l}\text { Modelagem } \\
\text { Matemática }\end{array}$ & $\begin{array}{l}\text { A Modelagem Matemática como alternativa de ensino e } \\
\text { aprendizagem da Geometria na EJA. }\end{array}$ \\
\hline $\begin{array}{l}\text { Modelagem } \\
\text { Matemática }\end{array}$ & $\begin{array}{l}\text { O uso da modelagem matemática no ensino da Geometria. Estudo } \\
\text { de caso: EJA. }\end{array}$ \\
\hline $\begin{array}{l}\text { Números e } \\
\text { Operações }\end{array}$ & $\begin{array}{l}\text { Relações entre conhecimentos matemáticos escolares e } \\
\text { conhecimentos do cotidiano, forjadas na constituição de práticas de } \\
\text { numeramento na sala de aula da EJA. }\end{array}$ \\
\hline $\begin{array}{l}\text { Números e } \\
\text { Operações }\end{array}$ & $\begin{array}{l}\text { Profissionais fazendo matemática: o conhecimento de números } \\
\text { decimais de alunos pedreiros e marceneiros da EJA. }\end{array}$ \\
\hline $\begin{array}{l}\text { Números e } \\
\text { Operações }\end{array}$ & $\begin{array}{l}\text { Relações entre práticas de numeramento mobilizadas e em } \\
\text { constituição nas interações entre os sujeitos da EJA. }\end{array}$ \\
\hline $\begin{array}{l}\text { Números e } \\
\text { Operações }\end{array}$ & $\begin{array}{l}\text { Conhecimentos de alunos do programa de EJA relativos aos números } \\
\text { racionais na forma fracionária. }\end{array}$ \\
\hline
\end{tabular}




\begin{tabular}{|c|c|}
\hline $\begin{array}{c}\text { Sub } \\
\text { Categorias }\end{array}$ & Título das produções \\
\hline $\begin{array}{l}\text { Números e } \\
\text { Operações }\end{array}$ & $\begin{array}{l}\text { Educação Matemática no ensino de ciências: contribuições da teoria } \\
\text { dos conjuntos na EJA - uma proposta metodológica. }\end{array}$ \\
\hline $\begin{array}{l}\text { Números e } \\
\text { Operações }\end{array}$ & Ensino de frações na EJA: obstáculos didáticos e epistemológicos. \\
\hline Outros & $\begin{array}{l}\text {...A minha vida seria muito diferente se não fosse a matemática... O } \\
\text { sentido e os significados do ensino de Matemática em processos de } \\
\text { exclusão e de inclusão Escolar e social na EJA. }\end{array}$ \\
\hline Outros & Matemática em rede a partir de projetos de pesquisa na EJA. \\
\hline Outros & O ensino de Matemática na EJA em escolas municipais de Santa Maria. \\
\hline Outros & Representações sociais de matemática: um estudo com alunos da EJA. \\
\hline Outros & $\begin{array}{l}\text { A investigação e produção de conhecimentos matemáticos com } \\
\text { significado na EJA: aprendizagem escolar e o cotidiano na formação de } \\
\text { jovens e adultos. }\end{array}$ \\
\hline Outros & $\begin{array}{l}\text { A experiência escolar de alunos jovens e adultos e sua relação com a } \\
\text { matemática. }\end{array}$ \\
\hline Outros & $\begin{array}{l}\text { O ensino de matemática na EJA: uma abordagem contextualizada do } \\
\text { tema transversal meio ambiente. }\end{array}$ \\
\hline Outros & $\begin{array}{l}\text { sobre a Matemática escolar produzidas por alunos de um } \\
\text { irno de EJA. }\end{array}$ \\
\hline Outros & $\begin{array}{l}\text { Matemática na EJA: uma proposta para trabalhadores da construção } \\
\text { civil. }\end{array}$ \\
\hline $\begin{array}{l}\text { Resolução de } \\
\text { problemas }\end{array}$ & $\begin{array}{l}\text { Concepções de professores e alunos sobre resolução de problemas } \\
\text { abertos como estratégia de ensino e aprendizagem da Matemática na } \\
\text { EJA: um estudo de caso de uma escola em Ceilândia - DF. }\end{array}$ \\
\hline $\begin{array}{l}\text { Resolução de } \\
\text { problemas }\end{array}$ & $\begin{array}{l}\text { Análise de atitudes de alunos na EJA em situação de resolução de } \\
\text { problemas. }\end{array}$ \\
\hline $\begin{array}{l}\text { Resolução de } \\
\text { problemas }\end{array}$ & $\begin{array}{l}\text { A argumentação Matemática na resolução de problemas de estrutura } \\
\text { aditiva com alunos de EJA. }\end{array}$ \\
\hline $\begin{array}{l}\text { Resolução de } \\
\text { problemas }\end{array}$ & $\begin{array}{l}\text { Estratégias usadas pelos alunos da EJA na resolução de problemas } \\
\text { aritméticos. }\end{array}$ \\
\hline $\begin{array}{l}\text { Resolução de } \\
\text { problemas }\end{array}$ & O ensino de funções através da resolução de problemas na EJA. \\
\hline $\begin{array}{l}\text { Resolução de } \\
\text { problemas }\end{array}$ & $\begin{array}{l}\text { ognitivas na resolução de problemas matemáticos: } \\
\text { com estudantes da EJA. }\end{array}$ \\
\hline $\begin{array}{l}\text { Resolução de } \\
\text { problemas }\end{array}$ & $\begin{array}{l}\text { Menos com menos é menos ou é mais? Resolução de problemas de } \\
\text { multiplicação e divisão de números inteiros por alunos do Ensino } \\
\text { Regular e da EJA. }\end{array}$ \\
\hline $\begin{array}{l}\text { Resolução de } \\
\text { problemas }\end{array}$ & Resolução de problemas e linguagem em EJA. \\
\hline $\begin{array}{l}\text { Tratamento da } \\
\text { Informação }\end{array}$ & $\begin{array}{l}\text { O educando da EJA: dificuldades e superações na aprendizagem de } \\
\text { matemática financeira. }\end{array}$ \\
\hline $\begin{array}{l}\text { Tratamento da } \\
\text { Informação }\end{array}$ & $\begin{array}{l}\text { EJA: uma aplicação da regra de três e porcentagem em cálculos } \\
\text { trabalhistas. }\end{array}$ \\
\hline $\begin{array}{l}\text { Tratamento da } \\
\text { Informação }\end{array}$ & $\begin{array}{l}\text { Matemática financeira e tecnologia: espaços para o desenvolvimento } \\
\text { da capacidade crítica dos educandos da EJA. }\end{array}$ \\
\hline $\begin{array}{l}\text { Tratamento da } \\
\text { Informação }\end{array}$ & $\begin{array}{l}\text { O papel das representações simbólicas no desenvolvimento do } \\
\text { raciocínio combinatório na EJA. }\end{array}$ \\
\hline
\end{tabular}


(conclusão)

\begin{tabular}{|l|l|}
\hline \multicolumn{1}{|c|}{$\begin{array}{c}\text { Sub } \\
\text { Categorias }\end{array}$} & \multicolumn{1}{|c|}{ Título das produções } \\
\hline $\begin{array}{l}\text { Tratamento da } \\
\text { Informação }\end{array}$ & $\begin{array}{l}\text { Análise combinatória na EJA: uma proposta de ensino a partir da } \\
\text { resolução de problemas. }\end{array}$ \\
\hline
\end{tabular}

(Fonte: Dados da pesquisa)

A categoria "Formação de Professores de Matemática" (D) reúne quatro dissertações: 1) Estudo com professores de matemática de jovens e adultos sobre suas práticas profissionais; saberes produzidos na ação de ensinar matemática na EJA. 2) Contribuições para o debate sobre a formação inicial de educadores matemáticos na UFPA. 3) A EJA na formação de professores de matemática: expectativas e desafios. 4) Concepções de EJA, de ensino e de aprendizagem de matemática de formadores de professores e suas implicações na oferta de formação continuada para docentes de matemática.

A categoria (E), reuniu os trabalhos relacionados ao "Currículo de Matemática" na EJA, está composta por oito dissertações: 1) Currículo de Matemática da EJA: análise de prescrições na perspectiva cultural da Matemática. 2) Professores de Matemática: como concebem o ensino na EJA? 3) Análise do material impresso de matemática do EJA1: reflexões baseadas no PNLD/EJA 2011. 4) As diferenças culturais dos alunos da EJA do Ensino Médio: uma visão etnomatemática. 5) Estudantes da EJA e materiais didáticos no ensino de matemática. 6) Práticas de numeramento nos livros didáticos de Matemática voltados para a EJA. 7) Uma análise curricular da matemática na EJA. 8) Uma proposta de educação matemática crítica e o resgate da cidadania junto aos alunos da EJA.

A análise dos resumos coletados evidenciou que há uma concentração de pesquisas relacionadas ao processo de ensino-aprendizagem de matemática, pois $67 \%$ das pesquisas mapeadas tratam de algum aspecto a ele relacionado. A resolução de problemas, a modelagem matemática, a etnomatemática e os jogos matemáticos foram metodologias estudadas para o ensino de matemática na EJA. Conteúdos matemáticos que integram os blocos: "Números e Operações", "Espaço e Forma", "Grandezas e Medidas", "Tratamento da Informação" também foram objeto de estudo das pesquisas inventariadas, além de outras temáticas como inclusão e exclusão, estratégias de ensino, cidadania, representações sociais, entre outras.

Quanto as pesquisas integrantes das categorias "Ensino-Aprendizagem de Estatística" (Categoria B) e "Formação de Professores de Matemática" (Categoria D) para a EJA a produção acadêmica é ainda pequena, pois cada uma delas representa apenas $6 \%$ do total de produções científicas mapeadas. As pesquisas inseridas na categoria "Atuação e prática do professor na EJA" representam 9\% e as inseridas na categoria "Currículo de Matemática para EJA", 12\%.

\section{ANÁLISE ESTRUTURAL DOS RESUMOS DAS PRODUÇÕES CIENTÍFICAS MAPEADAS COM O SOFTWARE IRAMUTEQ}


Na análise documental realizada nas etapas anteriores foi possível identificar os temas das produções científicas no contexto brasileiro sobre a EJA, relacionados à Matemática. No entanto, há outras possibilidades de análise dos resumos coletados. Para aprofundar a análise do conjunto dos resumos das pesquisas localizadas foi utilizado o software IRAMUTEQ, o qual nos possibilitou realizar uma análise lexical para identificar as palavras de maior frequência utilizadas nos resumos dessas pesquisas e, também, a análise de similitude a qual possibilitou identificar as coocorrências e as conexidades entre as palavras. Esse tipo de análise baseia-se na teoria dos grafos, sendo que a finalidade desse programa é descobrir a informação essencial contida no texto, através de uma análise textual. Segundo Camargo (2013b) embora esse tipo de análise de dados textuais seja quantitativo, também possibilita analisar a qualidade do fenômeno estudado.

O conjunto dos resumos das teses e dissertações foi organizado em um único texto (corpus), sendo cada um deles definido pelo programa IRAMUTEQ como "segmento de texto". O corpuséorganizado por linhas de comando denominadas de "linhas de astericos", nas quais são informados os números de identificação do texto, seguido de algumas variáveis indispensáveis para a realização da análise textual. Nesta pesquisa as variáveis foram chamadas de natureza, - natureza 1 para as dissertações, e natureza 2 para as teses -, e as categorias em cinco grupos: $A, B$, $C, D, E$, conforme os temas das pesquisas definidos anteriormente. Além disso, os textos que integram o corpus textual foram configurados conforme definido no tutorial IRAMUTEQ (Camargo, 2013a), principalmente quanto à acentuação, uso de caracteres especiais e formatação. O procedimento de organização das linhas de comando, para inserção das produções científicas, pode ser observado no exemplo do fragmento do resumo de uma dissertação:

$$
* * * * * \text { text_01 *diss_01 *cat_A }
$$

A EJA vem ganhando espaço nas pesquisas realizadas na área educacional. Existe uma preocupação grande em entender o processo de ensino por que passam essas pessoas que permaneceram muitos anos sem escolaridade ou afastados do sistema educacional. Para que possamos entender melhor esse processo e relevante uma investigação sobre a pratica dos professores que atuam na EJA, uma vez que são esses os principais responsáveis pelo processo de escolarização e pela aprendizagem dessa população e a sua reinserção no campo educativo. A particularidade deste trabalho esta em investigar como o professor de Matemática atua na EJA, buscando conhecer melhor suas visões sobre a Matemática, o seu ensino e também sobre a aprendizagem da Matemática por essa população. Para isso, além de observar a atuação docente desses profissionais procurou se conhece lós melhor através de entrevistas e da analise de um caso de ensino elaborado a partir de acontecimentos das salas de aula dos participantes da investigação. Os participantes da pesquisa foram três professores de Matemática que atuam na EJA em uma escola publica estadual de uma cidade do interior paulista e os alunos de uma de suas classes. Dadas as características dos participantes, a pesquisa se constituiu em três estudos de caso, cada um referente a um professor e sua classe. Para fundamentar esse estudo lancei mão de referenciais sobre os apoios legais que sustentam essa modalidade de ensino, sobre o perfil dessa clientela, sobre a situação do ensino de Matemática para esses alunos e sobre a formação básica e permanente dos professores que atuam nessa área. [...] ( CORPUS TEXTUAL DA PESQUISA, 2015, p.1) 
Após a inserção dos 68 resumos, cada um com uma linha de comando específica, o corpus textual foi revisado pelas pesquisadoras, salvo em formato TXT e inserido no IRAMUTEQ, programa que processa vários tipos de relatórios e possibilita várias formas de análise. Neste artigo serão apresentadas e discutidas somente duas delas:

a) a análise lexicográfica, que identifica as palavras denominadas de formas ativas, que são aquelas de maior frequência no corpus analisado;

b) a análise de similitude, que se baseia na teoria dos grafos e possibilita identificar as coocorrências entre as palavras e a conexidade entre elas.

\section{ANÁLISE LEXICOGRÁFICA}

Os resumos pertencentes às cinco categorias definidas inicialmente foram organizados em único texto, conforme define o manual do software IRAMUTEQ. O programa reconheceu $82,9 \%$ dos textos e a análise lexicográfica identificou a quantidade de palavras denominadas de formas ativas que apresentaram maior frequência no corpus textual analisado, as quais estão apresentadas no quadro 4:

Quadro 4 - Análise Lexicográfica - Formas ativas geradas no programa IRAMUTEQ - 2015

\begin{tabular}{|c|c|c|c|c|c|}
\hline Formas ativas & $\begin{array}{c}\text { Frequênci } \\
\text { a }\end{array}$ & Formas ativas & Frequência & Formas ativas & Frequência \\
\hline aluno & 214 & atividade & 73 & Processo & 43 \\
\hline Eja & 202 & trabalho & 70 & Conceito & 42 \\
\hline matemática & 185 & praticar & 70 & construção & 41 \\
\hline como & 164 & ao & 63 & Problema & 39 \\
\hline pesquisa & 144 & escola & 62 & Meio & 39 \\
\hline professor & 106 & utilizar & 60 & Dado & 39 \\
\hline aprendizagem & 92 & educação & 56 & Resultado & 38 \\
\hline analisar & 92 & sao & 54 & conheciment & 80 \\
\hline ensino & 82 & realizar & 54 & Proposta & 38 \\
\hline estudo & 80 & aula & 48 & estudante & 38 \\
\hline conhecimento & 80 & partir & 46 & Grupo & 36 \\
\hline
\end{tabular}

(Fonte: Relatório do software IRAMUTEQ - 2015)

As palavras que ocorreram com maior frequência estão representadas na nuvem de pontos (Figura 1), na qual o tamanho da fonte é proporcional à frequência das palavras no corpus textual analisado. Como o levantamento realizado foi sobre as teses e dissertações produzidas no Brasil relacionadas à EJA e Matemática, ficou evidente nas pesquisas realizadas a ênfase no "aluno", na "EJA", no ensino de "matemática", no "professor", na "aprendizagem", no "trabalho", pois essas palavras ou formas ativas se concentraram no centro da nuvem de pontos, revelando uma forte conexidade entre elas. 


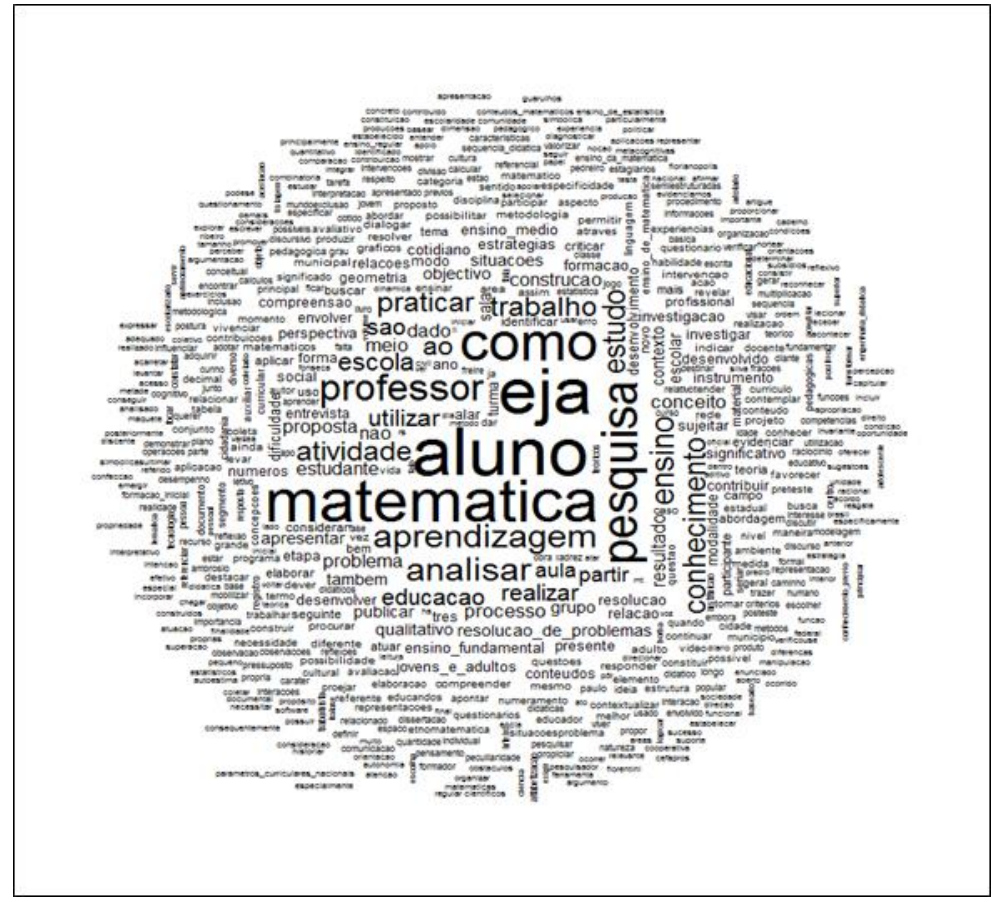

(Fonte: Relatório do software IRAMUTEQ - 2015)

A centralidade observada no "aluno" da EJA certamente é um dos elementos importante nas pesquisas devido às características desses sujeitos, com identidades tão diversificadas, formada atualmente por dois grupos de educandos: um, por pessoas mais maduras ou idosas que não tiveram acesso à educação escolar na idade certa, outro, por adolescentes excluídos do ensino regular devido a uma trajetória marcada pelo fracasso escolar. 
O primeiro grupo vê na escola uma perspectiva de integração sociocultural; o segundo mantém com ela uma relação de tensão e conflito aprendida na experiência anterior. Os jovens carregam consigo o estigma de alunosproblema, que não tiveram êxito no ensino regular e que buscam superar as dificuldades em cursos aos quais atribuem o caráter de aceleração e recuperação. Esses dois grupos distintos de trabalhadores de baixa renda encontram-se nas classes dos programas de escolarização de jovens e adultos e colocam novos desafios aos educadores, que têm que lidar com universos muito distintos nos planos etários, culturais e das expectativas sem relação à escola. (HADDAD; DI PIERRO, 2000, p.127).

Diante dessa realidade o professor de Matemática que atua na EJA geralmente se questiona em "como" ensinar alunos e alunas com diferentes histórias de vida e escolares, idades, experiências profissionais e ritmos de aprendizagem:

\begin{abstract}
$\mathrm{O}$ (a) aluno(a) jovem e adultos chega à sala de aula repleto de teorias, explicações e hipóteses. Sua família, a comunidade onde vive, seu trabalho e sua religiosidade permitiram-Ihe construir um sem-número de saberes. Cabe ao(à) professor(a) descobrir qual é esse corpo de conhecimentos, feito depura experiência e percepção, para a partir dele convidar seus alunos a acederem outras formas de pensar, explicar, fazer e agir.(BRASIL CADERNO2, 2006, p.7).
\end{abstract}

Nesse sentido, a escola além de um lugar por excelência de potencialização da aprendizagem dos alunos, representa na EJA "um espaço ao mesmo tempo de recolocação social, de sociabilidade, de formalização do saber e de desenvolvimento pessoal". (BRASIL - CADERNO2, 2006, p.8).

\title{
ANÁLISE DE SIMILITUDE
}

A análise de similitude realizada no IRAMUTEQ com o corpus textual possibilitou observar a conexidade ou a força de ligação entre os elementos expressos (palavras ativas) nos resumos das produções acadêmicas mapeadas. Pode-se observar na árvore máxima (Figura 2) a presença de três blocos distintos, com alto grau de conexidade entre as palavras: "Aluno, EJA e Matemática", de modo análogo à análise lexicográfica anteriormente discutida. Há forte coocorrência entre elas e outras palavras ativas formando uma rede na árvore máxima com linhas que se interligam as palavras "professor", "estudo", "aprendizagem", "trabalho", "ensino", "meio", "conhecimento", "pesquisa", "atividade", "escola", "analisar", "como", "praticar", "conceito", "utilizar", "aula".

No primeiro bloco, a palavra "Aluno" apresenta uma centralidade na árvore máxima construída com forte conexão com as palavras EJA e Matemática. Com análise da distribuição das palavras em torno de "Aluno" podemos observar algumas com uma forte ligação com as palavras: "pesquisa", "professor", "estudo", "aprendizagem", "trabalho", "meio", "conhecimento", "analisar", "atividade", "escola", "conceito".

Essas palavras se apresentam interligadas a outras de cunho didáticopedagógico: "processo", "educativo", "conhecimento prévio", "experiências", "contextualização", "produções", "cotidiano", "formativo", "emancipação", "formação", "profissional”, "exclusão", "cidadania", "currículo", "processo".

Também há forte ligação entre as palavras de conhecimento específico e pedagógico de matemática: "resolução de problemas", "linguagem", "situações- 
problema", "frações", "geometria", "equação", "etnomatemática", "combinatória", "Engenharia didática", "funções", "decimal”, "modelagem", "estatísticos", "dado", "áreas", "ensino de matemática”, "aplicações”.

Figura 2 - Árvore máxima gerada no software IRAMUTEQ - 2015.

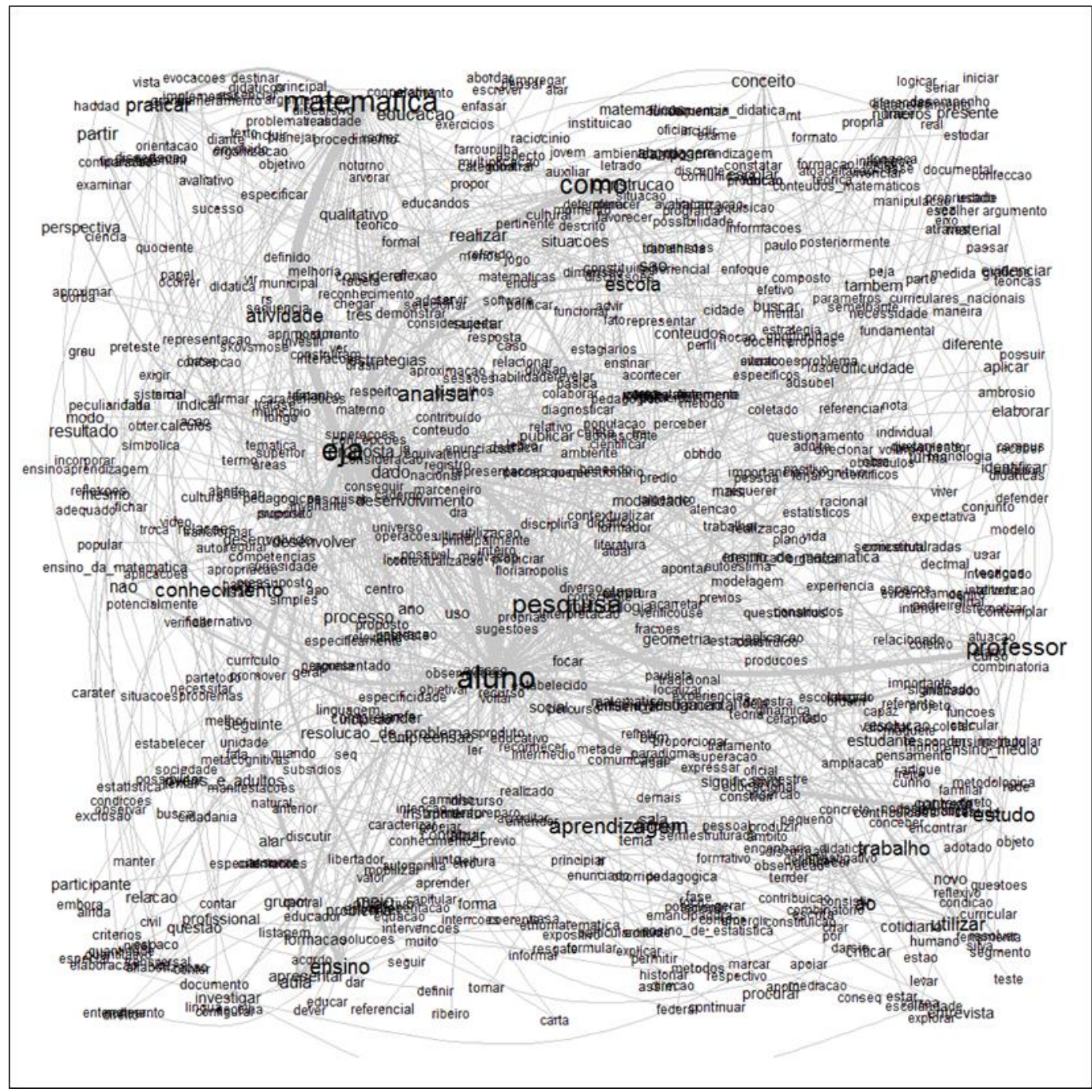

(Fonte: Relatório do software IRAMUTEQ - 2015)

Fica evidente nas relações entre as palavras ativas da árvore máxima que o processo de ensino-aprendizagem de Matemática na EJA pressupõe uma prática pedagógica que considere o aluno como sujeito ativo na construção de seu próprio conhecimento e o professor como mediador desse processo.

Os conceitos, procedimentos e atitudes relativos ao conhecimento matemático são elementos presentes nas pesquisas inventariadas, o que possibilita afirmar a importância dos conhecimentos específicos, pedagógicos e curriculares para a atuação do professor de matemática na EJA, uma vez que o segundo bloco da árvore de similitude o termo EJA se destaca como elemento aglutinador das palavras: "ensino", "conhecimento", "realização", "como", "matemática", "professor", "escola".

As palavras de cunho formativo e didático-pedagógico com forte ligação na árvore máxima são: "superação", "desenvolvimento", "competências", "relações", 
"cultura", "concepção", "estratégias", "currículo", "realizar" evidenciando as finalidades do ensino da Matemática, também nas dimensões culturais, sociais, formativos e políticas dos alunos adultos, aliadas as palavras ativas de cunho matemático: "dado", "áreas", "simbólica", "pré-teste", "divisão", "aproximação", "demonstrar", "matemáticas", "ciências", "situações", "reconhecimento", "conteúdos".

Observando o terceiro bloco na figura 2, a palavra Matemática tem forte ligação com a palavra EJA e Aluno, aglutinando as palavras de cunho pedagógico: "planejar", "educação" "procedimento", "objetivo", "realidade", "sucesso", "didática", "estratégias", "praticar", "examinar", "educandos", "realizar", "orientação" e as de conhecimento matemático: "exercício", "raciocínio", "problema", "situações", "jogo", "demonstrar", "reconhecimento", "pré-teste", "numeramento".

As análises lexicográficas e de similitude revelaram que nos resumos das produções científicas brasileiras, há prevalência de investigações que envolvem o processo ensino-aprendizagem de Matemática e as práticas pedagógicas dos professores.

\section{CONSIDERAÇÕES FINAIS}

Neste texto, ao tomar como ponto de partida o levantamento de teses e dissertações, foi possível apresentar uma breve análise das produções científicas no contexto brasileiro sobre a EJA, relacionadas à Matemática. Os trabalhos inventariados oferecem elementos importantes para compreender a história da produção de conhecimento e evidenciar as contribuições e lacunas nessa área de pesquisa em Educação Matemática, e ao mesmo tempo possibilitar que esse campo possa ser ainda bastante explorado pelos pesquisadores.

O conjunto de trabalhos analisados, ainda que de forma exploratória e preliminar, revelam alguns aspectos importantes:

a) as pesquisas realizadas no período 2004-2015 concentram-se na região sul e sudeste, com poucas investigações nas demais regiões brasileiras;

b) a maioria das pesquisas desenvolvidas tem como temas o processo ensinoaprendizagem de Matemática na EJA, com ênfase nas metodologias de ensino; resolução de problemas, jogos, modelagem matemática e nas áreas de geometria, tratamento da informação, números e operações;

c) as pesquisas sobre a formação de professores de matemática para atuação na EJA ainda são incipientes, desde que essa modalidade de ensino foi definida na LDBEN 9394/1996 no Brasil;

d) sobre o currículo de matemática para a EJA as pesquisas revelam uma há uma preocupação com o livro didático para essa modalidade de ensino, revelando uma perspectiva restrita de currículo;

e) na árvore máxima gerada no IRAMUTEQ sobre o conjunto de resumos fica evidente que há uma preocupação nas pesquisas com o perfil do aluno da EJA e suas relações com o conhecimento experiencial, com o cotidiano, com sua autoestima, com suas relações com o mundo do trabalho e, em como podem 
aprender e serem incluídos na sociedade como cidadãos, apesar das marcas da exclusão;

e) as conexidades das palavras na árvore máxima revelam que no corpus textual dos resumos das pesquisas analisadas predominam as questões que envolvem o aluno, o professor, a aprendizagem, o ensino, o conhecimento, as metodologias de ensino, dentre outros aspectos;

f) há necessidade de investigar com mais profundidade as pesquisas aqui inventariadas, considerando os aspectos históricos e conceituais da EJA relacionados à Matemática no contexto brasileiro. 


\title{
Mathematics in youth and adult education: analysis of scientific literature of the period 2004-2015
}

\begin{abstract}
This article presents the results of a qualitative study, which had a systematic review of scientific production character of mathematics in Youth and Adult Education - EJA, published in Brazil in the period 2004-2015. In the survey conducted by electronic means, were located 68 works, which were organized according to the type, year of publication, the home institution, the title and author. Following were grouped according to the similarity of the research subjects, a procedure that originated five categories: performance and practice math teacher; teaching and learning of Statistics; teaching and learning of mathematics; Mathematics teacher education and mathematics curriculum. The organization of all the summaries in one corpus textual and content analysis in IRAMUTEQ software, enabled the lexicographical and similarity analysis, showing the concentration of research on mathematics teaching and learning in adult education.
\end{abstract}

KEYWORDS: Mathematics. Adult education - EJA. Systematic review. 


\section{NOTAS}

1 Neste artigo, a partir deste parágrafo será utilizado a sigla EJA que é a abreviatura de Educação de Jovens e Adultos.

2 A linha de pesquisa Políticas Curriculares e Ensino de matemática é voltada ao estudo das questões contemporâneas sobre currículo e ensino de Matemática, em particular aos processos de organização e desenvolvimento curricular e suas relações com a formação inicial/continuada e atuação de professores de matemática. Para saber mais consultar: http://www3.uepg.br/geppea/.

3 A expressão "Educação de Jovens e Adultos" no título dos trabalhos mapeados foi substituída pela sigla "EJA", para fins de organização do texto.

4 A teoria dos grafos estuda objetos combinatórios - os grafos - que são um bom modelo para muitos problemas em vários ramos da matemática, da informática, da engenharia e da indústria. Muitos dos problemas sobre grafos tornaram-se célebres porque são um interessante desafio intelectual e porque têm importantes aplicações práticas. Para aprofundamento consultar: Uma introdução sucinta à teoria dos grafos http://www.ime.usp.br/ pf/teoriadosgrafos/ de autorias de P. Feofiloff Y. Kohayakawa Y. Wakabayashi (2011).

\section{REFERÊNCIAS}

BRASIL. Lei de Diretrizes e Bases da Educação Nacional. Lei no 9.394, de 20 de dezembro de 1996. Estabelece as diretrizes e bases da educação nacional. Diário Oficial da União, Brasília, 23 dez. 1996.

BRASIL. Ministério da Educação. Conselho Nacional de Educação/Câmara de Educação Básica. Parecer no 11 de 10 de maio de 2000. Brasília: MEC, 2000a. Diretrizes Curriculares Nacionais para a Educação e Jovens e Adultos.

BRASIL. Ministério da Educação. Conselho Nacional de Educação/Câmara de Educação Básica. Resolução no 01 de 05 de julho de 2000. Brasília: MEC, 2000b. Estabelece as Diretrizes Curriculares Nacionais para a Educação e Jovens e Adultos.

BRASIL. Ministério da Educação. Secretaria de Educação Fundamental. Educação para jovens e adultos - ensino fundamental - proposta curricular para o 10 segmento. Brasília: MEC, 2001. Disponível em: $<$ http://portal.mec.gov.br/index.php?option=com content\&id=13536\%3Amateri ais-didaticos\&ltemid=913>. Acesso em: 15 abr. 2015.

BRASIL. Ministério da Educação. Secretaria de Educação Fundamental. Proposta curricular para a educação de jovens e adultos - 20 segmento do ensino 
13534\%3Amaterial-da-proposta-curricular-do-2osegmento\&catid=194\%3Asecad-educacao-continuada\&Itemid=913>. Acesso em: 15 abr. 2015.

BRASIL. Ministério da Educação. Secretaria de Educação Continuada, Alfabetização e Diversidade. Coleção trabalhando com a educação de jovens e adultos. Brasília: MEC, 2006. Disponível em: <http://portal.mec.gov.br/expansaoda-rede-federal/194-secretarias-112877938/secad-educacao-continuada223369541/13536-materiais-didaticos>. Acesso em: 15 abr. 2015.

CAMARGO, B. V.; JUSTO, A. M. Tutorial para uso do software de análise textual iramuteq. Florianópolis: Universidade Federal de Santa Catarina, 2013a. 18 p.

CAMARGO, B. V.; JUSTUS, A. M. IRAMUTEQ: um software gratuito para análise de dados textuais. Temas em Psicologia, Florianópolis, v. 21, n.2, p.513-518, $2013 \mathrm{~b}$. Disponível em: <http://pepsic.bvsalud.org/pdf/tp/v21n2/v21n2a16.pdf>. Acesso em: 15 abr. 2015.

FEOFILOFF, Paulo et al. Uma introdução sucinta à teoria dos grafos. 2011. Disponível em:<http://www.ime.usp.br/ ppf/teoriadosgrafos>. Acesso em: 01 jul. 2015.

FERNANDES, Baltazar. Manual iramuteq. Tradução livre do manual de LucieLoubère e Pierre Ratinaud. 2014. Disponível em:

<http://www.iramuteq.org/documentation/fichiers/documentation_19_02_2014 .pdf>. Acesso em: 15 mai. 2015.

FERREIRA, Norma Sandra de Almeida. As pesquisas denominadas "estado da arte". Educação \& Sociedade, Campinas, ano XXIII, n.79, p.257-272, ago. 2000, p. 268.

HADDAD, Sergio; PIERRO Maria Clara Di. Escolarização de jovens e adultos. Revista Brasileira de Educação, Rio de Janeiro, n.14, p.108-194, mai./jun./jul./ago. 2000.

ROMANOWSKI, Joana Paulin. ENS, Romilda Teodora. As pesquisas denominadas do tipo "estado da arte" em educação. Diálogo Educacional, Curitiba, v.6, n.19, p.37-50, set./dez. 2006. no Brasil (2000-2006): mapeamento e problematizações. Revista Brasileira de Educação, Rio de Janeiro, v.14, n.40, p.7-23, jan./abr. 2006. 
APÊNDICE

Referências das produções acadêmicas sobre Matemática e EJA no período de 20042015.

(continua)

\begin{tabular}{|c|l|}
\hline n. & \multicolumn{1}{|c|}{ Referências } \\
\hline 1 & $\begin{array}{l}\text { ADELINO, Paula Resende. Práticas de numeramento nos livros didáticos de } \\
\text { matemática voltados para a educação de jovens e adultos. 2009. 134f. Dissertação } \\
\text { (Mestrado em Educação) - Universidade Federal de Minas Gerais, Belo Horizonte, } \\
2009 .\end{array}$ \\
\hline 2 & $\begin{array}{l}\text { ALBUQUERQUE, Regina Lúcia Tarquínio de. A matemática sob a ótica do tarô: uma } \\
\text { experiência com a educação de jovens e adultos. 2004. 150f. Dissertação (Mestrado } \\
\text { em Ensino de Ciências Naturais e Matemática) - Universidade Federal do Rio Grande } \\
\text { do Norte, Natal, 2004. }\end{array}$ \\
\hline 3 & $\begin{array}{l}\text { ALVES, Evanilson Landim. Menos com menos é menos ou é mais? Resolução de } \\
\text { problemas de multiplicação e divisão de números inteiros por alunos do ensino } \\
\text { regular e da educação de jovens e adultos. 2012. 205f. Dissertação (Mestrado em } \\
\text { Educação Matemática) - Universidade Federal do Pernambuco, Recife, 2012. }\end{array}$ \\
\hline 4 & $\begin{array}{l}\text { ALVES, Osvando do Santos. Saberes produzidos na ação de ensinar matemática na } \\
\text { EJA: contribuições para o debate sobre a formação de professores de matemática na } \\
\text { UFPA. 2004. 166f. Dissertação (Mestrado) - Universidade Federal do Pará, Belém, } \\
\text { 2004. }\end{array}$ \\
\hline 5 & $\begin{array}{l}\text { BARRETO, Fernanda Lopes Sá. O papel das representações simbólicas no } \\
\text { desenvolvimento do raciocínio combinatório na educação de jovens e adultos. 2012. } \\
\text { 104f. Dissertação (Mestrado em Educação Matemática e Tecnológica) - Universidade } \\
\text { Federal do Pernambuco, Recife, 2012. }\end{array}$ \\
\hline 6 & $\begin{array}{l}\text { BARROS, Ana Maria dos Santos. Educação matemática no ensino de ciências: } \\
\text { contribuições da teoria dos conjuntos na educação de jovens e adultos: uma } \\
\text { proposta metodológica. 2011. 170f. Dissertação (Mestrado Profissional em Ensino de } \\
\text { Ciências na Amazônia) - Universidade do Estado do Amazonas, Manaus, 2011. }\end{array}$ \\
\hline
\end{tabular}




\begin{tabular}{|c|c|}
\hline n. & Referências \\
\hline 7 & $\begin{array}{l}\text { ARROS, Cláudio Pousa Moraes. Análise de atitudes de alunos na educação de } \\
\text { vens e adultos em situação de resolução de problemas. 2008. 242f. Dissertação } \\
\text { lestrado Profissional em Ensino de Matemática) - Pontifícia Universidade } \\
\text { tólica de São Paulo, São Paulo, } 2008 \text {. }\end{array}$ \\
\hline 8 & $\begin{array}{l}\text { BORTOLLINI, Veridiana Rabaioli. Aprendizagem de geometria a partir de saberes, } \\
\text { vivências e interações de alunos da EJA numa escola pública. 2012. } 70 \text { f. } \\
\text { Dissertação (Mestrado em Educação em Ciências e Matemática) - Pontifícia } \\
\text { Universidade Católica do Rio Grande do Sul, Porto Alegre, 2012. }\end{array}$ \\
\hline 9 & $\begin{array}{l}\text { BRUNELLI, Osineia Albina. Concepções de EJA, de ensino e de aprendizagem de } \\
\text { matemática de formadores de professores e suas implicações na oferta de } \\
\text { formação continuada para docentes de matemática. 2012. 288f. Dissertação } \\
\text { (Mestrado em Educação) - Universidade Federal de Mato Grosso, Cuiabá, } 2012 \text {. }\end{array}$ \\
\hline 10 & $\begin{array}{l}\text { ABRAL, Viviane Ribeiro de Souza. Relações entre conhecimentos matemáticos } \\
\text { colares e conhecimentos do cotidiano forjadas na constituição de práticas de } \\
\text { umeramento na sala de aula da EJA. 2007. 169f. Dissertação (Mestrado em } \\
\text { lucação) - Universidade Federal de Minas Gerais, Belo Horizonte, } 2007 .\end{array}$ \\
\hline 11 & $\begin{array}{l}\text { a construção da cidadania na } \\
\text { professores que atuam no ensino } \\
\text { 2. } 281 \text { f. Dissertação (mestrado) - } \\
\text { 2012. }\end{array}$ \\
\hline 12 & $\begin{array}{l}\text { CAMILO, Flavio Augusto. O uso de vídeo no ensino de matemática: aplicações na } \\
\text { educação de jovens e adultos no ensino médio. 2011. 131f. Dissertação } \\
\text { (Mestrado em Ensino de Ciências e Matemática) - Universidade Cruzeiro do Sul, } \\
\text { São Paulo, } 2011 \text {. }\end{array}$ \\
\hline 13 & $\begin{array}{l}\text { CASTRO, Luís Roberto Cezar de. Narrativas sobre a matemática escolar } \\
\text { produzidas por alunos de um curso noturno de educação de jovens e adultos. } \\
\text { 2005. 113f. Dissertação (Mestrado em Educação) - Universidade do Vale do Rio } \\
\text { dos Sinos, São Leopoldo, } 2005 \text {. }\end{array}$ \\
\hline 14 & $\begin{array}{l}\text { RAGIOLI, Laíde. Conhecimentos de alunos do programa de educação de jovens } \\
\text { adultos relativos aos números racionais na forma fracionária. 2011. 147f. } \\
\text { ssertação (Mestrado em Educação Matemática) - Universidade Bandeirante de } \\
\text { o Paulo, São Paulo, } 2011 \text {. }\end{array}$ \\
\hline 15 & $\begin{array}{l}\text { CONTI, Keli Cristina. O papel da estatística na inclusão da educação de jovens e } \\
\text { adultos em atividades letradas. 2009. 227f. Dissertação (Mestrado) - } \\
\text { Universidade Estadual de Campinas, Campinas, 2009. }\end{array}$ \\
\hline 16 & $\begin{array}{l}\text { onstruídos pelos professores de matemática } \\
\text { o de jovens e adultos. 2006. 110f. Dissertação } \\
\text { do Pará, Belém, 2006. }\end{array}$ \\
\hline 17 & $\begin{array}{l}\text { COSTA, Luciano Pecoraro. Matemática financeira e tecnologia: espaços para o } \\
\text { desenvolvimento da capacidade crítica dos educandos da educação de jovens e } \\
\text { adultos. 2012. 140f. Dissertação (Mestrado Profissional em Educação } \\
\text { Matemática) - Universidade Federal de Juiz de Fora, Juiz de Fora, } 2012 \text {. }\end{array}$ \\
\hline 18 & $\begin{array}{l}\text { DANTAS, Jesica Barbosa. A argumentação matemática na resolução de } \\
\text { problemas de estrutura aditiva com alunos de EJA. 2011. 144f. Dissertação } \\
\text { (Mestrado em Educação) - Universidade Federal do Pernambuco, Recife, } 2011 \text {. }\end{array}$ \\
\hline
\end{tabular}




\begin{tabular}{|c|c|}
\hline n. & Referências \\
\hline 19 & $\begin{array}{l}\text { FARIA, Juliana Batista. Relações entre práticas de numeramento mobilizadas em } \\
\text { constituição nas interações entre os sujeitos da educação de jovens e adultos. } \\
\text { 2007. 335f. Dissertação (Mestrado em Educação) - Universidade Federal de Minas } \\
\text { Gerais, Belo Horizonte, } 2007 \text {. }\end{array}$ \\
\hline 20 & $\begin{array}{l}\text { FERREIRA, Edinalva Rodrigues. Ensino de frações na educação de jovens e adultos: } \\
\text { obstáculos didáticos e epistemológicos. 2014. 184f. Dissertação (Mestrado } \\
\text { Profissional em Educação Matemática) - Pontifícia Universidade Católica de São } \\
\text { Paulo, São Paulo, 2014. }\end{array}$ \\
\hline 21 & $\begin{array}{l}\text { FERREIRA, Reginaldo Botelho. O ensino de funções através da resolução de } \\
\text { problemas na educação de jovens e adultos. 2011. 143f. Dissertação (Mestrado } \\
\text { em Ensino de Ciências e Matemática) - Universidade Cruzeiro do Sul, São Paulo, } \\
2011 \text {. }\end{array}$ \\
\hline 22 & $\begin{array}{l}\text { FILHO, Lourival Alves Freitas. Estratégias usadas pelos alunos da educação de } \\
\text { jovens e adultos na resolução de problemas aritméticos. 2011. 144f. Dissertação } \\
\text { (Mestrado em Ensino de Ciências e Matemática) - Pontifícia Universidade Católica } \\
\text { de Minas Gerais, Belo Horizonte, } 2011 \text {. }\end{array}$ \\
\hline 23 & $\begin{array}{l}\text { FONSECA, Jussara Aparecida da. Análise combinatória na educação de jovens e } \\
\text { adultos: uma proposta de ensino a partir da resolução de problemas. 2012. 178f. } \\
\text { Dissertação (Mestrado em Ensino de Matemática) - Universidade Federal do Rio } \\
\text { Grande do Sul, Porto Alegre, } 2012 \text {. }\end{array}$ \\
\hline 24 & $\begin{array}{l}\text { FLORES, Sharon Rigazzo. Linguagem matemática e jogos: uma introdução ao } \\
\text { estudo de expressões algébricas e equações do 10 grau para alunos da EJA. } 2013 . \\
\text { 28f. Dissertação (Mestrado) - Universidade Federal de São Carlos, São Carlos, } 2013 .\end{array}$ \\
\hline 25 & $\begin{array}{l}\text { GODINHO, Maria da Penha Rodrigues de Oliveira. As diferenças culturais dos } \\
\text { alunos da educação de jovens e adultos do ensino médio: uma visão } \\
\text { etnomatemática. 2011. 189f. Dissertação (Mestrado) - Universidade Estadual } \\
\text { Paulista, Rio Claro, 2011. }\end{array}$ \\
\hline 26 & $\begin{array}{l}\text { GOMES, Adriana Aparecida Molina. Aprender matemática na educação de jovens } \\
\text { e adultos: a arte de sentir e dos sentidos. 2012. 370f. Tese (Doutorado em } \\
\text { Educação) - Universidade Estadual de Campinas, Campinas, } 2012 \text {. }\end{array}$ \\
\hline 27 & $\begin{array}{l}\text { GOMES, Maria José. Profissionais fazendo matemática: o conhecimento de } \\
\text { números decimais de alunos pedreiros e marceneiros da educação de jovens e } \\
\text { adultos. 2007. 204f. Dissertação (Mestrado) - Universidade Federal do } \\
\text { Pernambuco, Recife, } 2007 \text {. }\end{array}$ \\
\hline 28 & $\begin{array}{l}\text { INCHEGLU, Joni Matos. Uma proposta de educação matemática crítica e o resgate } \\
\text { da cidadania junto aos alunos da EJA. 2007. 94f. Dissertação (Mestrado em Ensino } \\
\text { de Ciências e Matemática) - Universidade Cruzeiro do Sul, São Paulo, } 2007 .\end{array}$ \\
\hline 29 & $\begin{array}{l}\text { JARA, Eduardo Janicsek. Matemática em rede a partir de projetos de pesquisa na } \\
\text { educação de jovens e adultos. 2008. 130f. Dissertação (Mestrado em Ensino de } \\
\text { Matemática) - Universidade Federal do Rio Grande do Sul, Porto Alegre, } 2008 \text {. }\end{array}$ \\
\hline 30 & $\begin{array}{l}\text { JANUARIO, Gilberto. Currículo de matemática da educação de jovens e adultos: } \\
\text { análise de prescrições na perspectiva cultural da matemática. 2012. 157f. } \\
\text { Dissertação (Mestrado em Educação Matemática) - Pontifícia Universidade } \\
\text { Católica de São Paulo, São Paulo, } 2012 \text {. }\end{array}$ \\
\hline 31 & $\begin{array}{l}\text { JUNIOR, Antonio Rafael Pepece. Análise da produção escrita de estudantes da EJA } \\
\text { em atividades algébricas. 2011. 117f. Dissertação (Mestrado em Ensino de Ciências } \\
\text { e Educação Matemática) - Universidade Estadual de Londrina, Londrina, } 2011 .\end{array}$ \\
\hline
\end{tabular}




\begin{tabular}{|c|c|}
\hline n. & Referências \\
\hline 32 & $\begin{array}{l}\text { KOORO, MériBello. Uma análise curricular da matemática na educação de jovens e } \\
\text { adultos. 2006. 122f. Dissertação (Mestrado em Ensino de Ciências e Matemática) - } \\
\text { Universidade Cruzeiro do Sul, São Paulo, } 2006 \text {. }\end{array}$ \\
\hline 33 & $\begin{array}{l}\text { LEITE, Eliana Alves Pereira. Estratégias metacognitivas na resolução de problemas } \\
\text { matemáticos: um estudo de caso com estudantes da educação de jovens e adultos. } \\
\text { 2011. 269f. Dissertação (Mestrado em Educação) - Universidade Federal de Mato } \\
\text { Grosso, Cuiabá, } 2011 \text {. }\end{array}$ \\
\hline 34 & $\begin{array}{l}\text { LIMA, Cibelle Lana Fórneas. Estudantes da EJA e materiais didáticos no ensino de } \\
\text { matemática. 2012. 137f. Dissertação (Mestrado) - Universidade Federal de Minas } \\
\text { Gerais, Belo Horizonte, 2012. }\end{array}$ \\
\hline 35 & $\begin{array}{l}\text { LIMA, Reinaldo Feio. Aprendizagem de estatística na EJA com tecnologia: uma } \\
\text { sequência didática com base nos registros de representação semiótica. 2014. } 128 \mathrm{f} \text {. } \\
\text { Dissertação (Mestrado em Educação em Ciências e Matemática) - Pontifícia } \\
\text { Universidade Católica do Rio Grande do Sul, Porto Alegre, } 2014 \text {. }\end{array}$ \\
\hline 36 & $\begin{array}{l}\text { LUTZ, Mauricio Ramos. Uma sequência didática para o ensino de estatística a alunos } \\
\text { do ensino médio na modalidade PROEJA. 2012. 152f. Dissertação (Mestrado em Ensino } \\
\text { de Matemática) - Universidade Federal do Rio Grande do Sul, Porto Alegre, } 2012 .\end{array}$ \\
\hline 37 & $\begin{array}{l}\text { MATTARA, Irmes Mary Moreno Roque. A investigação e produção de conhecimentos } \\
\text { matemáticos com significado na EJA: aprendizagem escolar e o cotidiano na formação } \\
\text { de jovens e adultos. 2010. 87f. Dissertação (Mestrado em Educação) - Universidade do } \\
\text { Oeste Paulista, Presidente Prudente, 2010. }\end{array}$ \\
\hline 38 & $\begin{array}{l}\text { MAZZANTI, David Luiz. Educação de jovens e adultos: uma aplicação da regra de três e } \\
\text { porcentagem em cálculos trabalhistas. 2008. 89f. Dissertação (Mestrado Profissional } \\
\text { em Ensino de Matemática) - Pontifícia Universidade Católica de São Paulo, São Paulo, } \\
2008 \text {. }\end{array}$ \\
\hline 39 & $\begin{array}{l}\text { MIGLIORANÇA, Fernanda. A atuação de professor de matemática na educação de } \\
\text { jovens e adultos: conhecendo a problemática. 2004. 183f. Dissertação (Mestrado em } \\
\text { Educação) - Universidade Federal de São Carlos, São Carlos, } 2004 \text {. }\end{array}$ \\
\hline 40 & $\begin{array}{l}\text { MONTEIRO, Eliziê Frans de Castro. Práticas avaliativas em matemática na educação de } \\
\text { jovens e adultos: estudo de caso de uma escola da rede municipal de Belo Horizonte. } \\
\text { 2010. 202f. Dissertação (Mestrado em Educação Matemática) - Universidade Federal de } \\
\text { Ouro Preto, Ouro Preto, 2010. }\end{array}$ \\
\hline 41 & $\begin{array}{l}\text { MOLON, Lorena. As aplicações e contribuições da geometria plana na educação de } \\
\text { jovens e adultos no ensino fundamental por meio de unidade de aprendizagem. } 2011 . \\
72 f \text {. Dissertação (Mestrado em Educação em Ciências Matemática) - Pontifícia } \\
\text { Universidade Católica do Rio Grande do Sul, } 2011 \text {. }\end{array}$ \\
\hline 42 & $\begin{array}{l}\text { NASCIMENTO, Monica Dias do. A contribuição do jogo de xadrez para o ensino de } \\
\text { coordenadas cartesianas na educação de jovens e adultos. 2011. 129f. Dissertação } \\
\text { (Mestrado em Ensino de Ciências) - Universidade Federal Rural de Pernambuco, Recife, } \\
2011 .\end{array}$ \\
\hline 43 & $\begin{array}{l}\text { NETO, João Monteiro do Sacramento. EJA: aprendizagem de conceitos através de } \\
\text { atividades práticas e conhecimento prévio. 2013. 88f. Dissertação (Mestrado } \\
\text { Profissional em Matemática) - Universidade Estadual de Santa Cruz, Ilhéus, } 2013 .\end{array}$ \\
\hline 44 & $\begin{array}{l}\text { OLIVEIRA, Rosalba Lopes de. A modelagem matemática como alternativa de ensino e } \\
\text { aprendizagem da geometria na educação de jovens e adultos. 2004. 191f. Dissertação } \\
\text { (Mestrado em Ensino de Ciências Naturais e Matemática) - Universidade Federal do Rio } \\
\text { Grande do Norte, Natal, 2004. }\end{array}$ \\
\hline
\end{tabular}


(continuação)

\begin{tabular}{|c|c|}
\hline n. & Referências \\
\hline 45 & $\begin{array}{l}\text { OLIVEIRA, Edimilson Antonio de. Concepções de professores e alunos sobre a resolução } \\
\text { de problemas abertos como estratégia de ensino e aprendizagem da matemática na } \\
\text { educação de jovens e adultos: um estudo de caso de uma escola em Ceilândia - DF. } \\
\text { 2007. 201f. Dissertação (Mestrado em Educação) - Universidade Católica de Brasília, } \\
\text { 2007. }\end{array}$ \\
\hline 46 & $\begin{array}{l}\text { OBST, Otilia Nair. Resolução de problemas e linguagem em EJA. 2015. 119f. Dissertação } \\
\text { (Mestrado em Educação) - Universidade Federal Paulista, Marília, } 2015 .\end{array}$ \\
\hline 47 & $\begin{array}{l}\text { PACHECO, Mirela Stefânia. Geometria plana e inclusão digital: uma experiência a partir } \\
\text { do cotidiano dos alunos EJA. 2009. 120f. Dissertação (Mestrado em Educação em } \\
\text { Ciências e Matemática) - Pontifícia Universidade Católica do Rio Grande do Sul, Porto } \\
\text { Alegre, } 2009 \text {. }\end{array}$ \\
\hline 48 & $\begin{array}{l}\text { PEREIRA, Roberto Carlos de Souza. O ensino de matemática na educação de jovens e } \\
\text { adultos: uma abordagem contextualizada do tema transversal meio ambiente. } 2013 . \\
\text { 20f. Dissertação (Mestrado Profissional em Ensino de Ciências) - Instituto Federal de } \\
\text { Educação, Ciência e Tecnologia, Nilópolis, } 2013 \text {. }\end{array}$ \\
\hline 49 & $\begin{array}{l}\text { PEREIRA, Daniele Esteves. Globos e mapas ao alcance das mãos: ensino de matemática } \\
\text { numa perspectiva de alfabetização funcional na EJA. 2008. 172f. Dissertação } \\
\text { (Mestrado em Educação) - Universidade Federal do Rio Grande do Norte, Natal, } 2008 .\end{array}$ \\
\hline 50 & $\begin{array}{l}\text { POMPEU, Carla Cristina. A experiência escolar de alunos jovens e adultos e sua relação } \\
\text { com a matemática. 2011. 125f. Dissertação (Mestrado em Educação) - Faculdade de } \\
\text { Educação da Universidade de São Carlos, São Paulo, } 2011 \text {. }\end{array}$ \\
\hline 51 & $\begin{array}{l}\text { RAMOS, Elenita Eliete de Lima. Propondo práticas e desafiando certezas: um estudo } \\
\text { em turma do PROEJA numa perspectiva de educação matemática crítica. 2011. 301f. } \\
\text { Tese (Doutorado) - Universidade Federal de Santa Catarina, Florianópolis, 2011. }\end{array}$ \\
\hline 52 & $\begin{array}{l}\text { REINHEIMER, Jeison Rodrigo. O uso da modelagem matemática no ensino da } \\
\text { Geometria. 2011. 110f. Dissertação (Mestrado em Ensino de Ciências Exatas) - Centro } \\
\text { Universitário UNIVATES, Lajeado, } 2011 \text {. }\end{array}$ \\
\hline 53 & $\begin{array}{l}\text { RODRIGUES, Ana Maria Sgrott. ...A minha vida seria muito diferente se não fosse a } \\
\text { matemática...: o sentido e os significados do ensino de matemática em processos de } \\
\text { exclusão e de inclusão escolar e social na educação de jovens e adultos. 2006. 213f. } \\
\text { Dissertação (Mestrado) - Universidade Federal do Pará, Belém, 2006. }\end{array}$ \\
\hline 54 & $\begin{array}{l}\text { RODRIGUES, Paulo Roberto. O ensino de matemática na EJA em escolas municipais de } \\
\text { Santa Maria. 2008. 268f. Dissertação (Mestrado em Educação) - Universidade Federal } \\
\text { de Santa Maria, Santa Maria, } 2008 \text {. }\end{array}$ \\
\hline 55 & $\begin{array}{l}\text { ROLOFF, Micheli Cristina Starosky. Representações sociais de matemática: um estudo } \\
\text { com alunos da educação de jovens e adultos. 2009. 145f. Dissertação (Mestrado em } \\
\text { Educação) - Universidade do Vale do Itajaí, Itajaí, 2009. }\end{array}$ \\
\hline 56 & $\begin{array}{l}\text { SANTANA, Luciana Getirana de. Análise do material impresso de matemática do PEJA: } \\
\text { reflexões baseadas no PNLD EJA 2011. 2011. 157f. Dissertação (Mestrado em } \\
\text { Educação) - Universidade Federal do Estado do Rio de Janeiro, Rio de Janeiro, } 2011 .\end{array}$ \\
\hline 57 & $\begin{array}{l}\text { SANTANA, Ivanilde da Conceição. Professores de matemática na educação de jovens e } \\
\text { adultos: pensamento geométrico no centro das atenções. 2010. 237f. Dissertação } \\
\text { (Mestrado em Educação) - Universidade de São Paulo, São Paulo, 2010. }\end{array}$ \\
\hline
\end{tabular}




\begin{tabular}{|c|c|}
\hline n. & Referências \\
\hline 58 & $\begin{array}{l}\text { SANTOS, Cleuza lara Campello dos. Inclusão-exclusão nas práticas } \\
\text { pedagógicas dos professores que ensinam matemática na educação de } \\
\text { jovens e adultos. 2008. } 143 \text { f. Dissertação (Mestrado) - Universidade Federal } \\
\text { do Rio Grande do Sul, Porto Alegre, } 2008 \text {. }\end{array}$ \\
\hline 59 & $\begin{array}{l}\text { SILVA, Maria Aparecida Delfino da. A etnomatemática em uma sala da EJA: a } \\
\text { experiência do pedreiro. 2007. 217f. Dissertação (Mestrado Profissional em } \\
\text { Ensino de Matemática) - Pontifícia Universidade Católica de São Paulo, São } \\
\text { Paulo, } 2007 \text {. }\end{array}$ \\
\hline 60 & $\begin{array}{l}\text { SILVA, Edgar Alves da. Introdução do pensamento algébrico para alunos do } \\
\text { EJA: uma proposta de ensino. 2007. 189f. Dissertação (Mestrado Profissional } \\
\text { em Ensino de Matemática) - Pontifícia Universidade Católica de São Paulo - } \\
\text { São Paulo, } 2007 .\end{array}$ \\
\hline 61 & $\begin{array}{l}\text { SILVA, Jeane do Socorro Costa da. Matemática na EJA: uma proposta para } \\
\text { trabalhadores da construção civil. 2006. 139f. Dissertação (Mestrado em } \\
\text { Educação em Ciências e Matemática) - Universidade Federal do Pará, Belém } \\
\text { do Pará, } 2006 \text {. }\end{array}$ \\
\hline 62 & $\begin{array}{l}\text { SILVA, José Vieira da. As dificuldades do uso do vídeo em aulas de matemática } \\
\text { na EJA no município de Goiânia-PE. 2006. 147f. Dissertação (Mestrado em } \\
\text { Ensino da Matemática) - Universidade Federal Rural de Pernambuco, Recife, } \\
2006 \text {. }\end{array}$ \\
\hline 63 & $\begin{array}{l}\text { SILVA, Kleber William Alves da. A educação de jovens e adultos na formação } \\
\text { de professores de matemática: expectativas e desafio. 2012. 221f. } \\
\text { Dissertação (Mestrado em Educação) - Universidade de São Paulo, São Paulo, } \\
2012 \text {. }\end{array}$ \\
\hline 64 & $\begin{array}{l}\text { SILVEIRA, Karla Beatriz Vivian. O educando da EJA: dificuldades e superações } \\
\text { na aprendizagem de matemática financeira. 2007, 143f. Dissertação } \\
\text { (Mestrado Profissional em Ensino de Física e de Matemática) - Centro } \\
\text { Universitário Franciscano, Santa Maria, } 2007 \text {. }\end{array}$ \\
\hline 65 & $\begin{array}{l}\text { SOUZA, Maria Celeste Reis Fernandes de. Gênero e matemática(s) - jogos de } \\
\text { verdade nas práticas de numeramento de alunas e alunos da educação de } \\
\text { pessoas jovens e adultas. } 2008 \text {. } 317 \mathrm{f} \text {. Tese (Doutorado em Educação) - } \\
\text { Universidade Federal de Minas Gerais, Belo Horizonte, } 2008 \text {. }\end{array}$ \\
\hline 66 & $\begin{array}{l}\text { SOUZA, Mazonilde Dalvina Costa de. A aprendizagem da geometria por meio } \\
\text { do estudo do cubismo no 5o ano da educação de jovens e adultos - EJA. } 2014 . \\
\text { 147f. Dissertação (Mestrado Profissional em Ensino de Ciências Exatas) - } \\
\text { Centro Universitário UNIVATES, Lajeado, } 2014 \text {. }\end{array}$ \\
\hline 67 & $\begin{array}{l}\text { THEES, Andréa. Estudo com professores de matemática de jovens e adultos } \\
\text { sobre suas práticas profissionais. 2012. 198f. Dissertação (Mestrado) - } \\
\text { Universidade Federal Fluminense, Niterói, 2012. }\end{array}$ \\
\hline 68 & $\begin{array}{l}\text { VERGETTI, Núbia. Professores de matemática: como concebem o ensino na } \\
\text { EJA?.2011. 111f. Dissertação (Mestrado em Educação) - Universidade Federal } \\
\text { Fluminense, Niterói, } 2011 \text {. }\end{array}$ \\
\hline
\end{tabular}


Recebido: 14 de jan. de 2016

Aprovado: 28 de mar. de 2016

DOI: $10.3895 /$ rbect.v9n1.3685

Como citar:

SILVA, G. C.; BRANDALISE, M. A. T. Matemática na Educação de Jovens e Adultos: análise da produção científica do período 2004-2015. Revista Brasileira de Ensino de Ciência e Tecnologia, v. 9, n. 1, p. 202227, jan./abr. 2016. Disponível em: <https://periodicos.utfpr.edu.br/rbect/article/view/3685>. Acesso em: $\mathrm{xxx}$

\section{Correspondência:}

Giane Correia Silva:

Rua Líbero Badaró, 5, 84032-150, Ponta Grossa

Mary Ângela Teixeira Brandalise:

Rua Tibúrcio Pedro Ferreira, 200, 84010-090, Ponta Grossa

Direito autoral: Este artigo está licenciado sob os termos da Licença Creative Commons-Atribuição 4.0 Internacional.

\section{(c) (1)}

